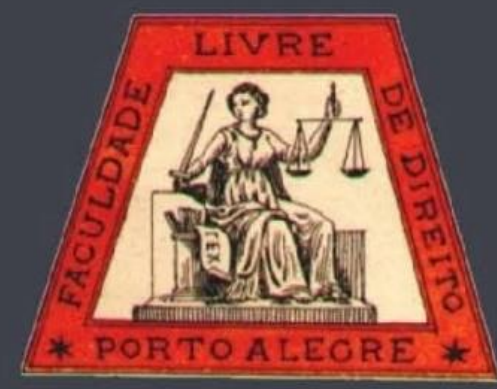

Da precariedade do acesso à saúde, das políticas públicas ineficazes e das técnicas clandestinas de modificação corporal utilizadas pelas travestis e mulheres trans

On the precauriouness of access to health, on the ineffective public policies and on the clandestine corporate modification techniques used by transvestites and trans-women

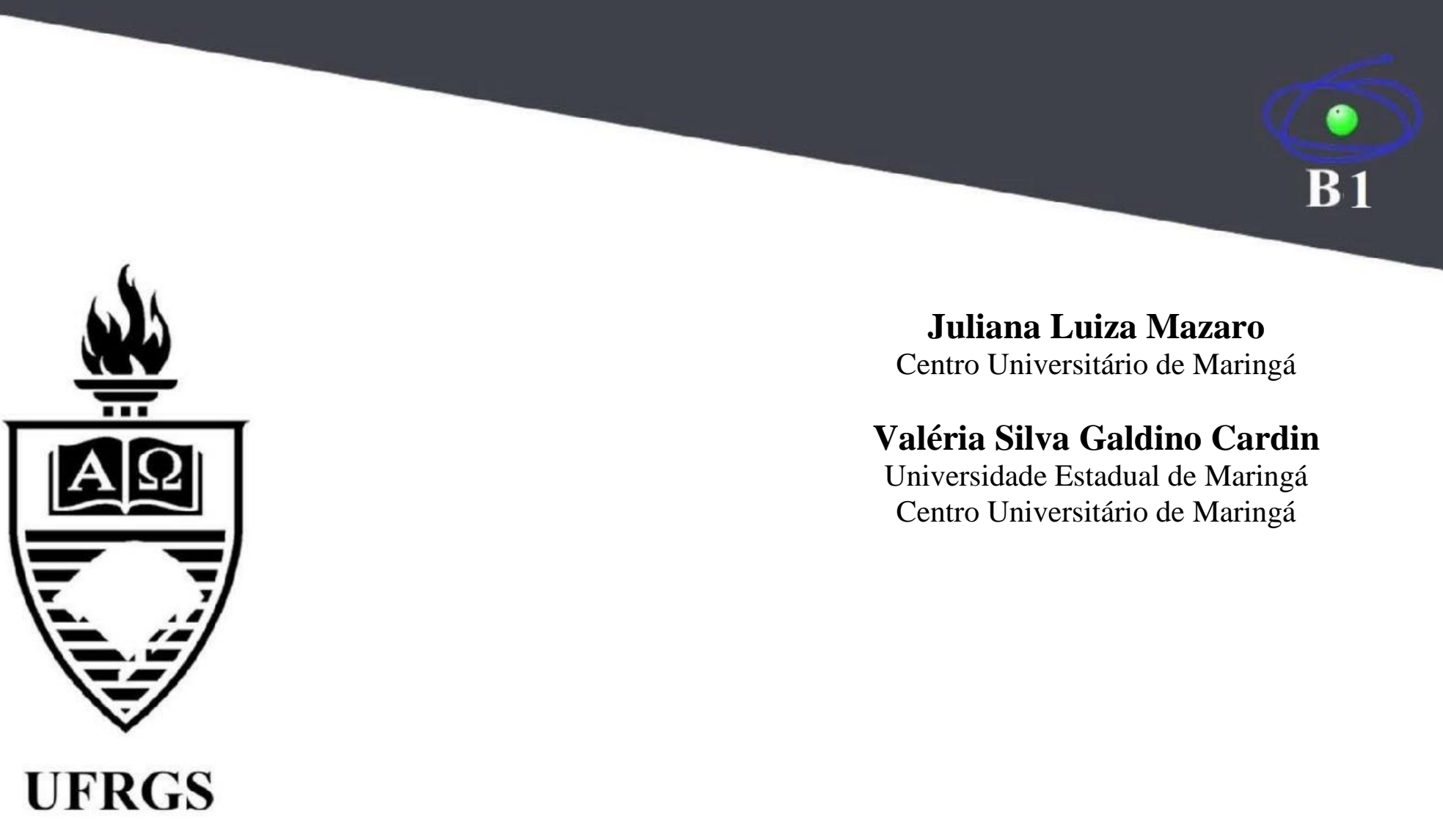




\title{
Da precariedade do acesso à saúde, das políticas públicas ineficazes e das técnicas clandestinas de modificação corporal utilizadas pelas travestis e mulheres trans
}

\author{
On the precauriouness of access to health, on the ineffective public policies and on the clandestine \\ corporate modification techniques used by transvestites and trans-women
}

Juliana Luiza Mazaro*

Valéria Silva Galdino Cardin ${ }^{* *}$

\section{REFERÊNCIA}

MAZARO, Juliana Luiza; CARDIN, Valéria Silva Galdino. Da precariedade do acesso à saúde, das políticas públicas ineficazes e das técnicas clandestinas de modificação corporal utilizadas pelas travestis e mulheres trans. Revista da Faculdade de Direito da UFRGS, Porto Alegre, n. 37, p. 146-165, dez. 2017.

\begin{abstract}
RESUMO
As travestis e os transexuais se submetem a métodos e procedimentos clandestinos de modelagem, automedicação hormonal e inoculação de silicone industrial líquido para adequarem seus corpos ao binarismo imposto pela heteronormatividade, por não reconhecerem o gênero que foi imposto pelo seu sexo biológico ao nascer, alterando assim a sua imagem externa para o gênero que se sentem pertencidos. Esta prática clandestina é realizada pelas "bombadeiras", que realizam os procedimentos sem o preparo profissional adequado e sem as condições mínimas de higiene. Estas pessoas aceitam e assumem os riscos do uso prolongado e excessivo dos hormônios femininos e da inserção em seu organismo de silicone líquido, em nome de seus objetivos, ou seja, um corpo feminino. O Brasil tem a maioria de suas políticas públicas de saúde voltadas para os heterossexuais. Para a comunidade LGBT existem apenas alguns programas de controle de DST e da AIDS, e na última década alguns mais específicos, mas insuficientes quanto ao número de serviços e ao número de atendimentos. Para as travestis e mulheres trans só há o Processo Transexualizador do SUS. Por fim, os transgêneros não possuem um acesso digno a saúde pública
\end{abstract}

\section{PALAVRAS-CHAVE}

Transgêneros. Precariedade da Sistema Público de Saúde. Políticas Públicas de Saúde Ineficazes.

\section{ABSTRACT}

Transvestites and transsexuals underwent clandestine methods and procedures of modeling, hormonal self-medication and inoculation of liquid industrial silicone to adapt their bodies to the binarism imposed by heteronormativity, since they do not recognize the gender that was imposed by their biological sex at birth, thus altering their external image to the genre they feel belonged to. This clandestine practice is carried out by the "bombadeiras", who carry out the procedures without proper professional preparation and without the minimum conditions of hygiene. These people accept and take the risks of prolonged and excessive use of female hormones and insertion of liquid silicone in their body, in the name of their goals, that is, a female body. Brazil has most of its public health policies aimed at heterosexuals. For the LGBT community there are only a few sexually transmitted diseases and AIDS control programs, and in the last decade some more specific but insufficient ones regarding the number of services and the number of visits. For transvestites and transgender women, there is only the Transexualization Process of SUS. Finally, transgenders do not have decent access to public health.

\section{KEYWORDS}

Transgender. Precariousness of the Public Health System. Ineffective Public Health Policies.

\section{SUMÁRIO}

Introdução. 1. Da sexualidade. 2. Do direito à sexualidade. 3. Do direito à imagem e do exercício da sexualidade pelas travestis e transexuais. 4. Da (re)construção do corpo pelas travestis e transexuais. 5. Da modificação corporal pelo uso

\footnotetext{
* Mestranda em Direito (Centro Universitário de Maringá - UniCesumar). Bacharel em Direito (Universidade Paranaense, 2015). Bacharel em Enfermagem (Faculdade Estadual de Educação, Ciências e Letras de Paranavaí, 2010).

** Professora da Universidade Estadual de Maringá e do Centro Universitário de Maringá (UniCesumar). Doutora em Direito Civil (Pontifícia Universidade Católica de São Paulo - PUC-SP, 2002). Mestre em Direito (PUC-SP, 1997). Graduada em Direito (Universidade Estadual de Maringá, 1986).
} 
de hormônios. 6. Do uso de silicone líquido. 7. Dos perigos da utilização do silicone industrial líquido. 8. Das "Bombadeiras" e do exercício irregular da profissão. 9. Da construção de uma agenda de políticas públicas à comunidade LGBT 10. Da agenda existente de políticas públicas de saúde aplicáveis. 11. Do Processo Transexualizador do SUS. Conclusão. Referências.

\section{INTRODUÇÃO}

A sexualidade é um direito de personalidade que compreende o sexo, o gênero, a identidade de gênero e a orientação sexual. Contudo, esta é ainda tratada sob valores heteronormativos, não reconhecendo muitas vezes a diversidade de vivências que ela proporciona ao ser humano, gerando assim preconceitos.

Nesta diversidade de vivências se encontra a travestilidade e a transexualidade, cujos personagens não se encaixam nas regras da heterossexualidade, pois o gênero não corresponde àquele que seu corpo físico apresenta, acabando assim marginalizados. Com efeito, esses personagens buscam - para se sentirem aceitos - a (re)construção de seus corpos consoante os padrões e valores socioculturalmente estabelecidos para o gênero do qual se sentem pertencidos.

As modificações corporais, frequentemente, são acompanhadas de dor física e emocional, além do alto custo que, muitas vezes, não pode ser suportado pelo travesti e pelo transexual.

Hodiernamente, muitos travestis e transexuais não tem acesso ao nosso serviço único de saúde por ser precário, enquanto outros não suportam a demora para a concretização do sonho de realização da modificação corporal que almejam.

Assim, buscam outras alternativas que possam ajudar na construção do corpo e da aparência que desejam, se automedicando com hormônios femininos adquiridos em farmácias, modelando os seus corpos com silicone líquido industrial com a ajuda das conhecidas "bombadeiras".
Esta pesquisa busca discorrer acerca da precariedade do acesso aos sistema público de saúde, da ineficácia das políticas públicas e das técnicas clandestinas de modificação corporal utilizadas pelas travestis e mulheres trans.

Por fim, para esta pesquisa foi utilizado o método teórico que consiste na consulta de obras, artigos científicos, bem como de documentos eletrônicos que tratam do tema.

\section{DA SEXUALIDADE}

O tema sexualidade sempre foi permeado por mitos e tabus, razão pela qual, durante séculos, nunca se discutiu o tema como hoje. Esta deve ser entendida como uma condição inerente ao ser humano, que lhe possibilita vivenciar inúmeras experiências e construir uma identidade pessoal.

Michel Foucault afirma que a sociedade contemporânea é a que mais discute sobre sexo. $\mathrm{O}$ indivíduo é compelido a falar acerca da sua sexualidade nos mais variados campos do saber, como por exemplo, na medicina, na psicologia, na economia e no direito. ${ }^{1}$

A sexualidade é constituída de rituais, linguagem, desejos, símbolos, representações e significados ${ }^{2}$, por isso, não pode mais ser vista na perspectiva puramente biológica do indivíduo.

Para se estudar toda a complexidade que envolve o tema, faz-se necessário discorrer alguns conceitos importantes, como o sexo, que se refere à constituição biológica e morfológica do $\operatorname{ser}^{3}$,

\footnotetext{
${ }^{1}$ FOUCAULT, Michel. História da sexualidade I: A vontade de saber. 13. ed. Rio de Janeiro: Graal, 1999, p. 33-34.

${ }^{2}$ LEAL, Jeferson. O corpo é meu! A vida é minha! A construção corporal de mulheres transexuais. $2016.72 \mathrm{f} . \mathrm{TCC}$ (Graduação) - Curso de Serviço Social, Universidade Federal de Santa Catarina, Florianópolis, 2016, p. 30

${ }^{3}$ SILVA JUNIOR, Jonas Alves da. Uma explosão de cores: sexo, sexualidade, gênero e diversidade. In: VIEIRA, Tereza Rodrigues (Org.). Minorias Sexuais: Direitos e Preconceitos. Brasília: Consulex, 2012. Cap. 1, p. 11-27.
} 
como o órgão genital e os caracteres secundários que determinam quem é macho ou fêmea.

O gênero, por sua vez, é uma construção sociocultural, que expressa o que é feminino ou masculino. Por meio desta divisão simplista e binária, imposta pela maioria heterossexual, o gênero tem determinado, ao longo dos tempos, as funções e papéis sociais dos indivíduos pelo órgão sexual com o qual nascem.

Berenice Bento afirma que o corpo sexuado impõe ao gênero "[...] algo que as sociedades criam para significar as diferenças dos corpos sexualizados, assenta-se em uma dicotomia entre sexo (natureza) versus gênero (cultura)" ${ }^{4}$.

Já a orientação sexual pode ser descrita como a atração afetivo-sexual que uma pessoa sente em relação à outra, podendo uma pessoa ser heterossexual, homossexual, bissexual, pansexual e assexuado.

A heteronormatividade ainda é a medida que se impõe na construção da sexualidade dos seres, infelizmente, eivada de preconceitos e modelos comportamentais que marginalizam as demais orientações sexuais.

Segundo Francielle Lopes Rocha e Valéria Silva Galdino Cardin que:

As relações homoafetivas, ao possibilitarem a pluralidade das práticas afetivas e sexuais, afrontam não somente a heterossexualidade compulsória, mas rompem, diretamente, com o binarismo reducionista, que atribui à genitália a significação social dos corpos e a determinação da identidade do ser humano. ${ }^{5}$
A identidade de gênero diz respeito ao gênero pelo qual o indivíduo se reconhece, não sendo necessariamente coerente com o sexo biológico com qual nasceu.

Para Tereza Rodrigues Vieira, a identidade de gênero é:

[...] uma condição em que a pessoa nasce com sexo biológico de um gênero, mas se identifica com os indivíduos pertencentes ao gênero oposto, e considera isso como desarmônico e profundamente desconfortante. ${ }^{6}$

Por fim, a sexualidade não é algo abstrato e universal, que possa ser aplicável a todos da mesma forma. Assim, não é possível estudá-la em uma visão puramente biológica, sob pena de legitimar normas preconceituosos, rotulando os comportamentos em naturais e em desviantes não-naturais. $^{7}$

\section{DO DIREITO À SEXUALIDADE}

A sexualidade humana foi por muito tempo utilizada como fonte de poder, vigiada e sobrecarregada de regras e recomendações, contudo ignorada enquanto um direito fundamental. ${ }^{8}$

A liberdade sexual é um direito derivado da liberdade, em sentido amplo, que se encontra previsto no caput do art. $5^{\circ}$ da Constituição Federal, que também determina que todos são iguais perante a lei independentemente do sexo que possuem. ${ }^{9}$

\footnotetext{
${ }^{4}$ BENTO, Berenice. A reinvenção do corpo: sexualidade e gênero na experiência transexual. Rio de Janeiro: Garamond, 2006, p.86.

${ }^{5}$ ROCHA, Francielle Lopes; CARDIN, Valéria Silva Galdino. Do discurso do ódio contra as minorias sexuais como um instrumento de exclusão social. In: SIQUEIRA, Dirceu Pereira; AMARAL, Sérgio Tibiriçá (Org.). Democracia, $L i$ berdade e Justiça Social: Fundamentos para uma teoria jurídica do reconhecimento. Birigui: Boreal, 2015. Cap. X. p. 181-200, 182. ${ }^{6}$ VIEIRA, Tereza Rodrigues. Nome e sexo: mudanças no re- trabalho. gistro civil. 2. ed. São Paulo: Atlas, 2012, p. 158.

${ }^{7}$ MOTT, Luiz. Antropologia, teoria da sexualidade e direitos humanos dos homossexuais. Bagoas- estudos gays: gênero e sexualidades, Natal, v. 1, n. 1, p.1-15, jan. 2007. Disponível em: $<$ https://periodicos.ufrn.br/bagoas/article/view/2252/1685>. Acesso em: 04 nov. 2016, p. 4. ${ }^{8}$ FOUCAULT, Michel. História da sexualidade I: A vontade de saber. 13. ed. Rio de Janeiro: Graal, 1999, p. 38.

9 A terminologia "sexo", neste caso, deve ser entendida como gênero, homem ou mulher, não como o conceito de sexo apresentado no tópico de "Da sexualidade" do presente
}

Da precariedade do acesso à saúde, das políticas públicas ineficazes e das técnicas clandestinas de modificação corporal utilizadas pelas travestis e mulheres trans 
Maria Berenice Dias entende que o direito à pessoa, organização ou produto representa para o sexualidade é um direito de primeira geração jun- público [...] (tradução do autor)"11.

tamente com os direitos à liberdade e à igualdade,

Como representação externa, o aspecto fípois diz respeito à liberdade sexual do indivíduo e sico é importante para as travestis e mulheres trans do direito ao tratamento igualitário. A autora tam- porque possibilita que a sociedade as enxergue bém afirma que a sexualidade é um direito de ter- pelo que de fato são, ou seja, é a forma que têm de ceira geração, um direito de todos e de cada um, exteriorizar e manifestar seu verdadeiro gênero, que tem o fim de realizar toda a humanidade pelo aquele pelo qual se reconhecem. seu livre exercício e permitir a preservação da dignidade da pessoa. ${ }^{10}$

$\mathrm{Na}$ seara jurídica, a imagem está inserida

Logo, não se pode pensar que um indivíduo possa se desenvolver plenamente como ser humano sem que a sua sexualidade seja assegurada, pois esta faz parte da construção de sua identidade pessoal. Além disto, o exercício da sexualidade está intimamente relacionado com o direito da dignidade da pessoa humana, da liberdade e da igualdade.

\section{DO DIREITO À IMAGEM E DO EXERCÍ- CIO DA SEXUALIDADE PELAS TRAVES- TIS E TRANSEXUAIS}

A aparência de uma pessoa representa na maioria das vezes o seu gênero. E não se pode duvidar da importância que a imagem tem para as travestis e para as mulheres trans na construção de sua identidade de gênero e na forma como o restante da sociedade as reconhecem.

O Dicionário Oxford conceitua imagem como "[...] a representação da forma externa de uma pessoa ou coisa[...] a impressão geral que uma

\footnotetext{
${ }^{10}$ DIAS, Maria Berenice. Liberdade sexual e direitos humanos. Disponível em: <http://www.ibdfam.org.br/_img/congressos/anais/192.pdf>. Acesso em: 05 nov. 2016.

11 " [...] a representation of the external form of a person or thing $[. .$.$] the general impression that a person, organization,$ or product presents to de public [...]" Cf. SOANES, Catherine; STEVENSON, Angus (Ed.). Oxford Dictionary of English. 2. ed. Oxford: Oxford University Press, 2005. E-book.

${ }^{12}$ LOPES, Teresa Ancona. $O$ dano estético: responsabilidade civil. 3. ed. São Paulo: Revista dos Tribunais, 2004, p 55.

${ }^{13}$ SILVA, Ilza Andrade Campos; OLIVEIRA, José Sebastião de. Direito à imagem e liberdade de expressão à luz dos

direitos da personalidade. Revista Jurídica Cesumar: Mestrado, Maringá, v. 6, n. 1, p. 395-420, jan/jun. 2006. Disponível em: <http://periodicos.unicesumar.edu.br/index.php/revjuridica/article/view/319/178>. Acesso em: 04 nov. 2016, p. 404-405.

${ }^{14}$ A inteligibilidade dos gêneros demanda coerência e continuidade de normas (heteronormas) socialmente instituídas e mantidas quanto ao sexo, ao gênero, a prática sexual e ao desejo, expressões de gênero que são consideradas incoerentes e descontínuas são proibidas. Cf. BUTLER, Judith P. Problemas de gênero: feminismo e a subversão da identidade. 5. ed. Rio de Janeiro: Civilização Brasileira, 2013, p. 60. no rol dos direitos de personalidade e abrange não só a dimensão física mas a aparência estética ${ }^{12}$. Compreende este direito quaisquer sinais pessoais que individualize a pessoa, que a diferencie das demais, como por exemplo, os gestos, a voz, as expressões, abrangendo, também, a forma como o indivíduo é percebido pela comunidade onde está inserido $^{13}$.

É por isso que as travestis e as mulheres trans buscam mais do que (re)construir seus corpos pelas técnicas médicas, elas assumem todos as nuances do gênero pelo qual se identificam, os maneirismos, a linguagem corporal, a maneira de falar e agir.

\section{DA (RE)CONSTRUÇÃO DO CORPO PE- LAS TRAVESTIS E MULHERES TRANS}

A expressão do gênero, geralmente, se verifica pelas características físicas do sujeito, por meio da coerência ou da discordância dos comportamentos e práticas entre o sexo biológico e a identidade de gênero da pessoa ${ }^{14}$, pela modelação do 
corpo em razão dos padrões impostos ao masculino e ao feminino.

O gênero, como uma construção social, estabelece o papel social e define os padrões de comportamento, já estabelecidos no tempo pelas práticas culturais dos estereótipos masculino e feminino.

Contudo, nem sempre o indivíduo aceita o gênero que lhe é imposto pelo sexo biológico com o qual nasceu, o que faz com que não exista harmonia entre sua mente e seu corpo. Tal desarmonia se torna mais desconfortável quando os caracteres sexuais secundários começam a aparecer, fazendo com que a pessoa busque meios de (re)construir seu corpo, a fim de atender ao gênero com o qual se identifica.

Como um espaço de construções e experiências, o corpo hoje foge da rigidez heteronormativa como paradigma da sexualidade humana, para se tornar palco de transformações e reordenações sociais. Neste cenário, as travestis e as mulheres transexuais são exemplos da reconstrução do sentido dos gêneros, representada pela modificação e resignificação dos corpos biológicos. ${ }^{15}$

A travestilidade é uma das expressões que representa a incoerência entre o sexo, baseado no genital e o gênero. As travestis transitam entre o masculino e o feminino, nascem com o corpo biológico do homem, mas desejam atributos considerados femininos em sua imagem, tornam seus corpos ambíguos. Elas não se ressentem com o seu órgão genital, mas buscam incorporar características femininas, como formas mais arredondadas, seios e quadris maiores.

Os corpos são vistos por elas como uma forma de linguagem, além de uma forma de serem aceitas pela grupo. Francisco Jander de Sousa Nogueira e Adriano Gomes de León afirmam que "[...] é no corpo e através dele que as travestis se produzem e se (re)conhecem enquanto sujeitos"16, construindo sua identidade e sua imagem.

Nesse sentido, sustentam que:

\begin{abstract}
As travestis quase sempre desestabilizam normas e condutas em nossa sociedade, cruzam constantemente as fronteiras das normas regulatórias de gêneros e expõem um universo de diversidades sexuais. Ao mesmo passo em que as travestis vão inscrevendo outra identidade em cima dos seus corpos, subvertendo as normas, elas se submetem aos padrões de beleza impostos por nossa sociedade. ${ }^{17}$
\end{abstract}

Por sua vez, a transexualidade é entendida como a incoerência sentida pelo indivíduo entre o seu sexo biológico e o gênero pelo qual se identifica, sem grande influência dos aspectos afetivosexuais, como ocorre com as travestis.

A pessoa trans desde a primeira infância sente uma desconexão psíquica e emocional entre o gênero que lhe foi imposto ao nascer, com base em seu órgão genital, com aquele pelo qual de fato se reconhece, desejando ser vista e viver de acordo com este ${ }^{18}$, para isto, submete seu corpo pelas transformações necessárias para inteligibilidade de seu gênero real.

Entretanto, nem sempre as travestis conseguem (re)construir seus corpos e lhe dar o significado do gênero que desejam por meio dos serviços oficiais de saúde. O acesso à saúde é difícil, até mesmo pelo SUS, no qual os serviços são gratuitos, mas, muitas vezes, deficientes ou ineficientes, sem falar na falta de treinamento e, até mesmo, empatia por parte dos profissionais para atendimento dessa população.

\footnotetext{
15 DAVI, Edmar Henrique Dairell. Belíssima: um estudo vista Latinoamericana de Estudios Sobre Cuerpos, Emocio merleau-pontyano da corporalidade travesti. 2013. 184 f. nes y Sociedad, Córdoba, v. 4, n. 8, p.55-67,abr/ jul. 2012, Tese (Doutorado) - Curso de Psicologia, Universidade de p.59. São Paulo, Ribeirão Preto, 2013, p. 31.

${ }^{16}$ NOGUEIRA, Francisco Jander de Sousa; LEÓN, Adriano Gomes de. "Trabalhadas no feminino": um estudo sobre corpo, desejo e prostituição travesti em Fortaleza-CE. Re- 
Soma-se a isso, a ausência de políticas públicas voltadas à promoção da saúde deste grupo social e que incluam a alteração de seus corpos, e o seu baixo poder econômico, faz com que elas busquem alternativas mais baratas, porém mais arriscadas, para fabricação de seus corpos femininos.

\section{DA MODIFICAÇÃo CORPORAL PELO USO DE HORMÔNIOS}

A ingestão de hormônios femininos é muito comum entre as travestis e as mulheres trans, e marca o início de sua transformação corporal, que ajuda no arredondamento de suas formas, no aumento das mamas, em geral, ajudam no aparecimento de alguns caracteres sexuais secundários femininos enquanto atrasa o aparecimento dos masculinos.

Porém, na maioria das vezes o início do consumo de hormônios não acontece por prescrição médica, mas pela indicação de travestis ou mulheres trans mais velhas, que já usam hormônios femininos há muito tempo. Elas, geralmente, utilizam grandes doses de anticoncepcionais e medicamentos para menopausa, que são facilmente adquiridos em farmácias sem receita. ${ }^{19}$

Larissa Pelúcio esclarece que:

[...] o hormônio circulando pelo sangue limpa a travesti daquilo que é masculino: pêlos, pele grossa, traços angulosos. Atribui a elas também qualidades morais vistas como próprias da mulher: sensibilidade, delicadeza e até mesmo dedicação ao lar. ${ }^{20}$
A hormonioterapia feita por meio da automedicação, é prática comum entre as travestis e pessoas trans, pois permite que modifiquem seu corpo para atender ao gênero que se sentem pertencidas, ajudando a (re)construir a imagem que desejam para si e que entendem ser necessária para a sua aceitação social.

No Processo Transexualizador do SUS a terapia hormonal é oferecida no pré e pós-operatório, nas unidades que atendem as demandas ambulatoriais $^{21}$. Segundo o Conselho Federal de Medicina o acompanhamento endocrinológico é obrigatório por dois anos, além de ser supervisionada pelo restante da equipe multidisciplinar, para que seja selecionada para a cirurgia de transgenitalização ${ }^{22}$.

Anne Rafaele Telmira Santos assevera que:

No que tange ao processo de construção corporal, na hormonioterapia os remédios Androcur junto com Acetado de Ciproterona aparecem como a medicação mais desejada. Atuam na diminuição do hormônio testotesterona, responsável pelo desenvolvimento dos caracteres sexuais masculinos, como os pelos, agindo na diminuição das características ditas masculinas. A construção do corpo feminino ao ser iniciada na adolescência, fez com que as transexuais se automedicassem a fim de conseguir as curvas, a boa pele, os seios, enfim, todas as características de um corpo dito feminino $[\ldots] .{ }^{23}$

Os hormônios são essenciais na vida das travestis e mulheres trans, em geral começam utilizando-os por conta própria e sob a orientação de pessoas conhecidas que já praticam ou praticaram

\begin{abstract}
${ }^{19}$ SANTOS, Anne Rafaele Telmira. A experiência da hormonioterapia das transexuais em Maceió/AL. Latitude, Maceió, v. 7, n. 1, p.129-147, jun. 2013. Disponível em: $<$ http://www.seer.ufal.br/index.php/latitude/article/view/1068>. Acesso em: 19 dez. 2016, p. 136.

${ }^{20}$ PELÚCIO, Larissa. "Toda quebrada na plástica": Corporalidade e construção de gênero entre travestis paulistas Campos, Curitiba, v. 6, n. 1-2, p.97-112, 31 dez. 2005. Universidade Federal do Parana. Disponível em: <http://revistas.ufpr.br/campos/article/view/4509/3527>. Acesso em: 25 out. 2016, p. 101.
\end{abstract}

${ }^{21}$ BRASIL. Ministério da Saúde. Portaria $n^{o} 2.803$, de 19 de novembro de 2013. Redefine e amplia o Processo Transexualizador no Sistema Único de Saúde (SUS). Brasíla, DF: DOU, 21 nov. 2015. v. 226, Seção 1, p. 25

${ }^{22}$ CONSELHO FERAL DE MEDICINA. Resolução $n^{o}$ 1.955 de maio de 2010. Dispõe sobre a cirurgia de transgenitalismo e revoga a Resolução CFM no 1.652/02. Diário Oficial da União. Brasília, 3 set. 2010, Seção I. p. 109-110.

${ }^{23}$ SANTOS, Anne Rafaele Telmira. A experiência da hormonioterapia das transexuais em Maceió/AL. Latitude, Maceió, v. 7, n. 1, p.129-147, jun. 2013. Disponível em: $<$ http://www.seer.ufal.br/index.php/latitude/article/view/1068>. Acesso em: 05 maio 2017, p. 132. 
a auto-hormonização e assim permanecem fazendo uso por toda sua vida. Todavia, há aquelas que buscam o Processo Transexualizador do SUS ou procedimentos particulares, e passam a ter acesso a uma hormonioterapia orientada por um especialista em endocrinologia.

Em comum, entre as que continuam se hormonizando informalmente e as que utilizam serviços oficiais é o desejo de adequarem seus corpos a sua identidade pessoal, de serem mulheres.

\section{DO USO DE SILICONE LÍQUIDO}

O silicone é amplamente difundido e utilizado tanto pelas mulheres como pelos homens para a modificação corporal, ou seja, aumentar volumes e corrigir imperfeições, atendendo aos desejos individuais da pessoa de modelar seu corpo para atender os valores e padrões estéticos da sociedade contemporânea.

Pode-se definir o silicone como um composto semi-orgânico que contém simultaneamente grupos orgânicos ligados a uma coluna inorgânica. Formado por átomos de silício na cadeia principal combinado com oxigênio e ligado à radicais orgânicos, cuja fórmula bruta é $\mathrm{R}_{2} \mathrm{SiO}$, o que lhe rende propriedades únicas que permite sua utilização em vários campos, inclusive na área da saúde, devido a sua biocompatibilidade. ${ }^{24}$

\footnotetext{
${ }^{24}$ COLAS, André. Silicones: Preparation, Properties and Performance. Disponível em: <https://www.dowcorning.co.kr/ko_KR/content/publishedlit/01-3077.pdf $>$.

Acesso em: 05 nov. 2016, p. 2.

${ }^{25}$ DORNELAS, Marilho Tadeu et al. Siliconomas. Rev. Bras. Cir. Plást., São Paulo, v. 26, n. 1, p.16-21, jan/mar. 2011. Disponível em: <http://www.scielo.br/scielo.php?script=sci_arttext $\&$ pid=S1983-

51752011000100005>. Acesso em: 03 nov. 2016, p. 16.

${ }^{26}$ PELÚCIO, Larissa. "Toda quebrada na plástica": Corporalidade e construção de gênero entre travestis paulistas. Campos, Curitiba, v. 6, n. 1-2, p.97-112, 31 dez. 2005. Universidade Federal do Parana. Disponível em: <http://revistas.ufpr.br/campos/article/view/4509/3527>. Acesso em: 25 out. 2016, p. 100.

${ }^{27}$ Vive-se o momento da "sociedade do espetáculo", aquela na qual a imagem é vital, construída a partir de referências midiáticas, estereotipadas, criando "ilusões" e acabando com
}

O silicone foi descoberto no século XIX, mas foi só no início do século XX que começou a ser utilizado para fins estéticos e reparadores. O silicone líquido teve seu apogeu na década de 50 e nas duas décadas seguintes foi amplamente utilizado por médicos e leigos em todo o planeta, na forma de óleo e industrial, para aumentar as mamas e melhorar o contorno corporal. Contudo, houve inúmeras complicações, que variavam desde a migração para outras partes do corpo até a manifestação de câncer. ${ }^{25}$

Larissa Pelúcio assevera que as travestis (e aqui se insere as mulheres trans também) são constantemente seduzidas pelos apelos da moda e padrões estéticos estabelecidos pela sociedade, e ao perseguirem a modificação de seus corpos reproduzindo estes valores procuram sua legitimação e integração social. ${ }^{26}$

$\mathrm{Na}$ busca para construir seus corpos conforme os referenciais e normas de beleza vigente, que neste momento histórico ${ }^{27}$ é um modelo hedonista ${ }^{28}$ que prega um corpo sensual e saudável, cosmetizado e fetichizado, as travestis e as pessoas trans acabam esbarrando em obstáculos financeiros, contextuais e biológicos. ${ }^{29}$

As travestis e as mulheres trans, que não estão inseridas no Processo Transexualizador do o "natural", o "autêntico" e o "espontâneo", inserindo o indivíduo em um palco, em uma encenação mais sedutora que a realidade. Cf. FREIRE FILHO, João. A sociedade do espetáculo revisitada. Revista Famecos, Porto Alegre, v. 10, n. 22, p.33-46, dez. 2003. Disponível em: <http://revistaseletronicas.pucrs.br/ojs/index.php/revistafamecos/article/view/3230/2494>. Acesso em: 06 nov. 2016, p. 33-34. ${ }^{28} \mathrm{O}$ modelo hedonista é aquele que afirma que o prazer (a satisfação de desejos) é o maior bem da humanidade e o melhor objetivo da vida. Cf. Cf. SOANES, Catherine; STEVENSON, Angus (Ed.). Oxford Dictionary of English. 2. ed. Oxford: Oxford University Press, 2005. E-book.

${ }^{29}$ NOGUEIRA, Francisco Jander de Sousa; LEÓN, Adriano Gomes de. "Trabalhadas no feminino": um estudo sobre corpo, desejo e prostituição travesti em Fortaleza-CE. Revista Latinoamericana de Estudios Sobre Cuerpos, Emociones y Sociedad, Córdoba, v. 4, n. 8, p.55-67,abr/ jul. 2012, p. 59. 
SUS ${ }^{30}$ e que não encontram em outros serviços regulamentados (públicos e privados) o acesso às modificações corporais que necessitam para desenvolver sua identidade de gênero ${ }^{31}$, costumam se submeter a aplicação do silicone industrial líquido de forma clandestina.

Esta reprodução envolve o consumo de hormônios femininos, em altas dosagens e sem acompanhamento profissional, que ajudará com que elas tenham suas formas mais arredondadas, a voz mais fina, etc. No entanto, em geral, estas modificações são demoradas e não atingem o objeto almejado, fazendo com que busquem as próteses de silicone, e na falta de recursos o silicone industrial líquido.

As travestis com melhor poder aquisitivo, chamadas de "top" ou "européias", costumam realizar suas modificações corporais em cirurgiões plásticos renomados e usam próteses de silicone regulamentadas $^{32}$, o que na comunidade lhes dão um destaque maior, como se estivessem hierarquicamente superior às outras. Diante disto há um aumento na procura pelo silicone industrial líquido pelas demais, que as admiram.

Quando se fala nesse material, que é utilizado clandestinamente pelas pessoas que desejam modelar seu corpo, mas que por razões econômicas não podem recorrer a uma clínica oficial e credenciada, deve-se ter em mente que se trata de um ${ }^{30}$ BRASIL. Ministério da Saúde. Portaria $n^{o} 2.803$, de 19 de
novembro de 2013. Redefine e amplia o Processo Transexu-
alizador no Sistema Único de Saúde (SUS). Brasíla, DF:
DOU, 21 nov. 2015. v. 226, Seção 1, p. 25.
31 PAIVA, André Luiz dos Santos; FÉLIX-SILVA, Antônio
Vladimir. Produção Protética dos Corpos: Experiências
TRANS e Políticas de Saúde. Ártemis, João Pessoa, v. 18, n.
1, p.251-263, 31 dez. 2014. Revista Artêmis. Disponível em:
<http://periodicos.ufpb.br/index.php/artemis/arti-
cle/view/22550/12513>. Acesso em: 03 nov. 2016, p. 252.
32 PELÚCIO, Larissa. "Toda quebrada na plástica": Corpo-
ralidade e construção de gênero entre travestis paulistas.
Campos, Curitiba, v. 6, n. 1-2, p.97-112, 31 dez. 2005. Uni-
versidade Federal do Parana. Disponível em: <http://revis-
tas.ufpr.br/campos/article/view/4509/3527>. Acesso em: 25
out. 2016, p. 99 .

${ }^{33}$ DAVI, Edmar Henrique Dairell. Belíssima: um estudo merleau-pontyano da corporalidade travesti. 2013. $184 \mathrm{f}$. líquido que não é estéril, nem puro, de aspecto oleoso, grosso, incolor e inodoro, muito usado na fabricação de peças automotivas e na construção civil. ${ }^{33}$

Devido a natureza líquida e espessa do referido produto, este é injetado no corpo das pacientes com agulhas de uso veterinário, de grosso calibre com espessura de uma ponta de lápis, que nem sempre são descartáveis. Algumas vezes, há aplicação de anestésico local comprado em farmácias, os orifícios que ficam após a aplicação (de diâmetro considerável devido ao calibre da agulha), são fechados com supercolas e papel. ${ }^{34}$

Esta aplicação, geralmente, é feita por travestis mais velhas, que já passaram pelo procedimento, conhecidas como "bombadeiras" devido ao movimento de bombear que fazem na seringa para que o silicone penetre no corpo da paciente. ${ }^{35 ; 36}$

O processo é arriscado e doloroso, sendo conhecido como a "dor da beleza", dor essa que se justifica para que elas atinjam o corpo desejado, isto é, mais feminino, com formas redondas e volumosas, e para que defendam a atuação das bombadeiras. ${ }^{37}$

Além disso, o silicone líquido é de fácil acesso e pode ser comprado em lojas de autopeças, armarinhos, mercados e na rede mundial de computadores, sem qualquer necessidade de identificação ou credenciamento para isto. Em uma pesquisa

Tese (Doutorado) - Curso de Psicologia, Universidade de São Paulo, Ribeirão Preto, 2013, p. 48.

${ }^{34}$ Brasil é recordista mundial com 1,5 milhão de cirurgias plásticas ao ano (Profissão Repórter). Direção de Caco Barcellos. [s.i]: Globo Produções, 2015. Color.

${ }^{35}$ Ibid., p. 48.

${ }^{36}$ PELÚCIO, Larissa. "Toda quebrada na plástica": Corporalidade e construção de gênero entre travestis paulistas. Campos, Curitiba, v. 6, n. 1-2, p.97-112, 31 dez. 2005. Universidade Federal do Parana. Disponível em: <http://revistas.ufpr.br/campos/article/view/4509/3527>. Acesso em: 25 out. 2016, p. 102.

${ }^{37}$ NOGUEIRA, Francisco Jander de Sousa; LEÓN, Adriano Gomes de. "Trabalhadas no feminino": um estudo sobre corpo, desejo e prostituição travesti em Fortaleza-CE. Revista Latinoamericana de Estudios Sobre Cuerpos, Emociones y Sociedad, Córdoba, v. 4, n. 8, p.55-67,abr/ jul. 2012, p. 57. 
em cinco sites de vendas online, houve uma variação de preços entre $\mathrm{R} \$ 14,90$ e $\mathrm{R} \$ 29,90$ para o frasco de um litro do produto, sem restrições de compra e com possibilidade de parcelamento em um dos anunciantes. ${ }^{38}$

Ocorre que, ainda que as travestis e as mulheres trans saibam dos riscos da inserção do silicone industrial líquido em seus corpos, elas se submetem aos procedimentos com as "bombadeiras", pois seu desejo em ter o corpo (re)construído dentro do modelo do gênero pelo que se reconhecem e dos valores a estes impostos pela sociedade se sobrepõe aos perigos.

\section{DOS PERIGOS DA UTILIZAÇÃO DO SILI- CONE INDUSTRIAL LÍQUIDO}

O silicone industrial não é próprio para aplicação no organismo humano, porque é cheio de impurezas, podendo causar inúmeros problemas de saúde na pessoa que o inserir em seu corpo, podendo até levar à morte.

Ao ser injetado no corpo do indivíduo, esse produto é reconhecido pelo organismo como um corpo estranho, não podendo ser fagocitado pelo sistema imune. Muitas vezes acaba sendo encapsulado e transformado em uma substância pétrea, endurecida e irregular, envolta por uma fibrose calcificada, conhecida como siliconoma. ${ }^{39}$

A aplicação do produto não é feita em ambientes controlados e regulamentados pela Agência Nacional de Vigilância Sanitária (ANVISA). Comumente são feitas no domicílio da própria paciente ou da "bombadeira" sem qualquer condição

\footnotetext{
${ }^{38}$ Os sites pesquisados foram "Mercado Livre" (www.mercadolivre.com.br); "Extra" (www.extra.com.br); "Submarino" (www.submarino.com.br); "Lojas Americanas" (www.americanas.com.br); e, "Natural fitness" (www.naturalfitness.com.br).

${ }^{39}$ DORNELAS, Marilho Tadeu et al. Siliconomas. Rev. Bras. Cir. Plást., São Paulo, v. 26, n. 1, p.16-21, jan/mar. 2011. Disponível em: <http://www.scielo.br/scielo.php?script=sci_arttext $\&$ pid=S1983-

51752011000100005>. Acesso em: 03 nov. 2016, 17/19.
}

de esterilidade e às vezes com higiene precária, o que por si só pode causar infecções graves locais e sistêmicas.

Marilho Tadeu Dornelas et. al. define as complicações em:

[...] precoces, advindas das aplicações sem os cuidados básicos de assepsia e antissepsia, tais como infecções e necroses teciduais, e tardias, ocorrendo a migração do produto pelo sistema linfático, venoso ou mesmo pela força da gravidade, migrando para outras regiões. ${ }^{40}$

Daniel Francisco Mello e outros cirurgiões especificam mais algumas adversidades que podem surgir da aplicação do silicone industrial no corpo humano:

As complicações locais após injeções de silicone líquido industrial vão desde alterações na coloração e consistência da pele com a formação de nódulos e granulomas a intenso processo inflamatório, com necrose e ulcerações, formação de abscessos e fístulas eliminação do material injetado, retrações e deformidades cicatriciais.

Devido ao potencial elevado de migração do material, relacionado à utilização de maiores volumes, as alterações teciduais podem ser identificadas em locais distantes daqueles em que o silicone foi injetado. $\mathrm{O}$ acometimento de linfonodos regionais e a infiltração de tecidos adjacentes podem ser encontrados em longo prazo. Afecções respiratórias como o edema pulmonar e a pneumonite são descritas como complicações sistêmicas e podem ocasionar o óbito. ${ }^{41}$

Esse produto é uma solução acessível, tanto pelo valor, quanto pela disponibilidade em lojas físicas e online, tornando-se uma ferramenta quase indispensável na (re)construção do corpo das travestis e pessoas trans. ${ }^{42}$ Torna-se um líquido sagrado no processo de produção do corpo feminino,

\footnotetext{
${ }^{40}$ Ibid., p. 16.

${ }^{41}$ MELLO, Daniel Francisco et al. Complicações locais após a injeção de silicone líquido industrial: série de casos. Rev. Col. Bras. Cir, Rio de Janeiro, v. 40, n. 1, p.37-43, fev. 2013. Disponível em: <http://www.scielo.br/pdf/rcbc/v40n1/07.pdf>. Acesso em: 05 nov. 2016, p. 41.

${ }^{42}$ NOGUEIRA, Francisco Jander de Sousa; LEÓN, Adriano Gomes de. "Trabalhadas no feminino": um estudo sobre
} 
pois ter seios siliconados, quadris moldados, coxas grossas e rostos refeitos ajudam na criação do feminino e cristaliza a concepção binária dos gêneros impostas pela heteronormatividade.

Verifica-se que, apesar dos riscos enumerados acima, as travestis e as mulheres trans se submetem e continuarão se submetendo a aplicação em seus corpos desta substância, aceitando o preço da dor e até da morte para (re)criarem a imagem do gênero feminino, preferencialmente, aquele imposto pela mídia e pela sociedade.

\section{DAS “BOMBADEIRAS" E DO EXERCÍCIO IRREGULAR DA PROFISSÃO}

As "bombadeiras" são as pessoas que realizam o procedimento de inoculação do silicone líquido no corpo das travestis ou pessoas trans, conhecidas por este nome porque o silicone industrial líquido é viscoso e para injetá-lo na paciente estas mulheres fazem o movimento de "bombar" o êmbolo da seringa.

Quando realizam este procedimento estético, as "bombadeiras" estão desempenhando uma atividade privativa dos médicos, conforme determina o art. $4^{\circ}$, incisos II e III da Lei $n^{\circ} 12.842 / 20013$ :

Art. 4ำ São atividades privativas do médico:

II - indicação e execução da intervenção cirúrgica e prescrição dos cuidados médicos pré e pósoperatórios;

III - indicação da execução e execução de procedimentos invasivos, sejam diagnósticos, terapêuticos ou estéticos, incluindo os acessos vasculares profundos, as biópsias e as endoscopias (grifo nosso).
A cirurgia plástica estética e reparadora é a especialidade que cuida da modificação estética do corpo, como a implantação do silicone, sendo reconhecida pela Resolução no 1.845/2008 do Conselho Federal de Medicina (CFM), determinada pelo convênio deste com a Associação Médica Brasileira (AMB) e a Comissão Nacional de Residência Médica (CNRM).

Desta forma, a atividade das "bombadeiras", além de não ser regulamentada pela União ${ }^{43}$, invade o campo da medicina, constituindo crime nos termos do arts. $282^{44}$ e 284 , inciso $\mathrm{I}^{45}$ do Código

Penal Brasileiro e afrontando o que determina o art. $5^{\circ}$, inciso XIII da Constituição Federal "é livre o exercício de qualquer trabalho, ofício ou profis-

são, atendidas as qualificações profissionais que a lei estabelecer" (grifo do autor).

Mesmo quando causam lesões corporais graves nas clientes, dificilmente uma delas irá denunciá-la ou processá-la, pois esse público sabe que se trata de uma prática ilegal e mesmo assim procuram os serviços das "bombadeiras".

Desde que a "bombadeira" não leve a "paciente" a óbito, dificilmente será combatida sua prática pelas autoridades, a ponto que demande uma investigação e, por conseguinte um processo criminal. Diante disto, somado a facilidade de acesso ao silicone industrial e a demanda constante de clientes, continuam exercendo ilegalmente atividades privativas da medicina.

\section{DO ACESSO À SAÚdE E DA CONSTRU- ÇÃO DE UMA AGENDA DE POLÍTICAS PÚ- BLICAS À COMUNIDADE LGBT}

\footnotetext{
corpo, desejo e prostituição travesti em Fortaleza-CE. Revista Latinoamericana de Estudios Sobre Cuerpos, Emociones y Sociedad, Córdoba, v. 4, n. 8, p.55-67,abr/ jul. 2012, p. 60.

${ }^{43}$ Constituição Federal determina no art. 22. Compete privativamente à União legislar sobre:[...] XVI - organização do sistema nacional de emprego e condições para o exercício de profissões.

${ }^{44}$ Art. 282 - Exercer, ainda que a título gratuito, a profissão de médico, dentista ou farmacêutico, sem autorização legal

ou excedendo-lhe os limites: Pena - detenção, de seis meses a dois anos. Parágrafo único - Se o crime é praticado com o fim de lucro, aplica-se também multa.

${ }^{45}$ Art. 284 - Exercer o curandeirismo: I - prescrevendo, ministrando ou aplicando, habitualmente, qualquer substância; [...] Pena - detenção, de seis meses a dois anos. Parágrafo único - Se o crime é praticado mediante remuneração, o agente fica também sujeito à multa. 
A agenda de políticas públicas próprias da comunidade LGBT no Brasil ainda é incipiente, se comparada àquelas voltadas para a coletividade heterossexual e até mesmo para outras minorias e grupos vulneráveis. Ações e programas específicos para as travestis e transexuais são ainda mais escassos.

O estabelecimento da saúde como um direito de todos os cidadãos e um dever do Estado, através de serviços públicos de acesso universal, pela Constituição Federal, foi um grande avanço para área da saúde no Brasil. ${ }^{46}$ Com a criação do Sistema Único de Saúde a promoção, a proteção e a recuperação da saúde da população entra de vez na agenda pública e política nacional, em todos os níveis de governo da República. ${ }^{47}$

A saúde deve ser compreendida para além de um organismo livre de doenças, mas como resultante de condições e acesso à serviços adequados e suficientes de alimentação, educação, habitação, saneamento básico, trabalho, lazer, etc. Possui natureza estrutural e decorre de lutas empreendidas entre a sociedade e o Estado, do qual se exige meios de efetivação do direito à saúde. ${ }^{48}$

O Brasil começa a se preocupar com a saúde LGBT com o crescimento da epidemia de DST/AIDS na década de 1980, e as políticas públicas de combate e prevenção a disseminação das doenças sexualmente transmissíveis e do vírus HIV permanecem por muito tempo sendo as únicas preocupações governamentais com esta população.

Há pouco mais de uma década é que a agenda nacional de políticas de saúde passou a se preocupar com a atenção integral à saúde LGBT, iniciando com o "Programa Brasil sem Homofobia”, em 2004. ${ }^{49}$

Em 2008, a concepção integral de atendimento à saúde deste grupo social passa a ser formalmente tratada pela "Política Nacional de Saúde Integral de Lésbicas, Gays, Bissexuais, Travestis e Transexuais (LGBT)", que reconhece as complexidades e especificidades da saúde desta população, por meio de ações que visam à eliminação dos preconceitos e das desigualdades, garantindo o acesso universal, integral e igualitário das pessoas. ${ }^{50}$

Contudo, a política de atenção integral não substitui as políticas voltadas às DST/AIDS, elas se complementam, até porque as últimas, ainda, são a principal (em alguns municípios a única) porta de acesso da população LGBT ao SUS. ${ }^{51}$

A atenção integral busca atender a comunidade LGBT com ações e serviços mais abrangentes, do que aquelas abrangidas pelas políticas de combate e prevenção de doenças, estimulando a

\footnotetext{
${ }^{49}$ BRASIL. Ministério da Saúde. Conselho Nacional de Combate à Discriminação. Brasil Sem Homofobia: Programa de combate à violência e à discriminação contra GLTB e promoção da cidadania homossexual. Brasília: Ministério da Saúde, 2004.

${ }^{50}$ BRASIL. Ministério da Saúde. Portaria n ${ }^{\circ} 2.836$, de 01 de dezembro de 2011. Institui, no âmbito do Sistema Único de Saúde (SUS), a Política Nacional de Saúde Integral de Lésbicas, Gays, Bissexuais, Travestis e Transexuais (Política Nacional de Saúde Integral LGBT).

${ }^{51}$ PERILO, Marcelo et al. Entre a AIDS e a integralidade: travestis, transexuais, bissexuais, lésbicas e gays nas políticas públicas de saúde no Brasil. In: BORGES, Lenise Santana (Coord.). Políticas públicas para população LGBT no Brasil: um mapeamento crítico preliminar. Goiânia: UFG, 2009. Cap. 6. p. 213-256. Disponível em: <https://www.sertao.ufg.br/up/16/o/politicaslgbt_saúde.pdf?1345091830>. Acesso em: 28 nov. 2016, p. 232.
} 
promoção e a prevenção da saúde, além do aspecto curativo. Busca a (re)construção da cidadania e dos direitos do público atendido, que por sua vez é mais amplo do que os contemplados pelas ações de DST/AIDS.

Todavia, a agenda de políticas públicas de saúde LGBT ainda é escassa e enfrenta falta de orçamento e o constante preconceito em muitas das esferas do Poder Executivo, que impedem a implantação de ações e programas que de fato surtam efeitos significativos para os membros desta população.

Assim, o que se tem visto é que em curto prazo a agenda nacional de atenção integral a saúde LGBT, é insuficiente. Logo, faz-se necessário propor discussões para a formulação de políticas de saúde continuadas, fortalecendo o diálogo contra preconceitos, por meio da capacitação dos profissionais de saúde e de propostas que fomente a (re)construção da cidadania e dos direitos destas pessoas.

10 DA AGENDA EXISTENTE DE POLÍTICAS PÚBLICAS DE SAÚDE APLICÁVEIS

Por muito tempo, o cenário nacional de políticas públicas de saúde para a comunidade LGBT era voltado apenas à educação em saúde, com o fim de diminuir dentre os indivíduos as doenças sexualmente transmissíveis (DST) e a síndrome da imunodeficiência adquirida (AIDS).

Entretanto, após o Plano Nacional de Promoção da Cidadania e Direitos Humanos LGBT, que trouxe a diretriz de implantação da Política Nacional de Saúde Integral de LGBT (PNSI/LGBT), instituída pela Portaria no 2.836/2011 do Ministério da Saúde, é que se pretendeu uma mudança na atenção a saúde das travestis e pessoas trans.

\footnotetext{
${ }^{52}$ BRASIL. Ministério da Saúde. Travesti e Resteito - Cartilha "Ser Travesti”. Brasília, DF, 2016. Disponível em: < http://www.aids.gov.br/sites/default/files/anexos_campanhas/2010/42751/cartilha.pdf>. Acesso em: 06 nov. 2016.
}

Quanto às modificações corporais, tema deste trabalho, a PNSI/LGBT tem objetivos que incluem a redução dos riscos associados à ingestão prolongada e excessiva de hormônios, devendo o Ministério Público elaborar protocolos clínicos acerca do uso de hormônios e a colocação de próteses de silicone para as travestis e pessoas trans.

Em relação à utilização do silicone industrial líquido apenas uma campanha foi encontrada, trata-se de uma cartilha do Programa Nacional de DST e AIDS com o título "Ser Travesti" da campanha "Travesti e Respeito" 52 , que trata do perigo da inoculação deste produto no organismo humano. Outra cartilha que aborda o silicone líquido é a do Ministério da Saúde, da campanha "Cuidar bem da saúde de cada um. Faz bem para todos, Faz bem para o Brasil - Saúde Trans", esta, contudo, apenas faz menção sobre sua utilização pelas travestis e mulheres trans. ${ }^{53}$

É notória a ausência de políticas públicas de saúde que visam diminuir os índices da utilização do silicone industrial líquido na (re)construção do corpo dessas pessoas, bem como o de controle de riscos.

Ressalte-se que, em relação à ingestão prolongada e excessiva de hormônios, devido à automedicação e da inserção de silicone industrial no organismo humano o Estado aguarda que haja complicações que obriguem as travestis e/ou mulheres trans a buscarem os serviços de saúde, normalmente, os relacionados à urgência e emergência para que atue.

Nestes casos, a pessoa será tratada segundo os protocolos e políticas públicas de urgência e emergência, que cuidará dos sintomas e doenças já consequentes à inoculação do silicone no corpo.

Marilho Tadeu Dornelas afirma que o diagnóstico, na maioria das vezes, é clínico, auxiliado por alguns exames complementares, como os de

${ }^{53}$ BRASIL. Ministério da Saúde. Cuidar bem da saúde de cada um. Faz bem para todos, Faz bem para o Brasil. Brasília, DF, 2016. Disponível em: <http://portalsaude.saude.gov.br/images/pdf/2016/fevereiro/18/CARTILHA-Equidade-10x15cm.pdf $>$. 
laboratório, de imagem, etc. O tratamento é longo, pode ser apenas medicamentoso ou, em casos mais graves, pode ser necessário várias cirurgias, além da possibilidade de deixar sequelas estéticas e funcionais. ${ }^{54}$

Ficou comprovado que muitas travestis e mulheres trans mesmo conhecendo os riscos da automedicação hormonal e do uso do silicone industrial líquido não se escusam de assumi-los, insistindo nestas práticas na busca incessante de um corpo feminino e da beleza.

\section{DO PROCESSO TRANSEXUALIZADOR DO SUS}

O Processo Transexualizador do SUS é uma das muitas políticas públicas de saúde que objetivam cumprir os mandamentos constitucionais de que a saúde é um direito social de todos e da Lei $\mathrm{n}^{\circ} 8.080 / 1990$ que garante a universalidade dos serviços do Sistema Único de Saúde.

Esta política governamental procura garantir

[...] o atendimento integral de saúde a pessoas trans, incluindo acolhimento e acesso com respeito aos serviços do SUS, desde o uso do nome social, passando pelo acesso à hormonioterapia, até a cirurgia de adequação do corpo biológico à identidade de gênero e social. ${ }^{55}$
Infelizmente, este programa é eivado de preconceitos, as travestis e pessoas trans que recorrem a estes serviços de saúde pública são tratadas como portadoras de desvios psicológicos permanente de identidade (CID 10, F64.0 ${ }^{56}$ ). A Resolução n ${ }^{\circ}$ 1.955/2010 do CFM ainda considera a transexualidade como uma patologia. ${ }^{57}$

Além disto, é extremamente burocrático e demorado, mesmo para aquelas que não desejam a cirurgia de transgenitalização, como confirma Jeferson Leal:

O modelo burocrático obriga que as pessoas transexuais e/ou travestis passem pelas equipes multidisciplinares pelos protocolos hospitalares/ambulatoriais. São acompanhadas e observadas, para ao final de dois anos, aquelas que desejarem, receberem o diagnóstico de transexualismo. ${ }^{58}$

Outro aspecto crítico do Processo Transexualizador do SUS é o pequeno número de hospitais e ambulatórios habilitados para execução dos serviços, apenas cinco instituições nosocomiais e seis ambulatoriais, distribuídas por todo território brasileiro. 59

A rede de serviços é dividida em duas linhas de cuidado, conforme o art. $3^{\circ}$ da Portaria $n^{\circ}$

\footnotetext{
${ }^{54}$ DORNELAS, Marilho Tadeu et al. Siliconomas. Rev. Bras. Cir. Plást., São Paulo, v. 26, n. 1, p.16-21, jan/mar. 2011. Disponível em: <http://www.scielo.br/scielo.php?script=sci_arttext\&pid=S1983-

51752011000100005>. Acesso em: 03 nov. 2016, p. 20.

${ }^{55}$ BRASIL. Ministério da Saúde. Cuidar bem da saúde de cada um. Faz bem para todos, Faz bem para o Brasil. Brasília, DF, 2016. Disponível em: <http://portalsaude.saude.gov.br/images/pdf/2016/fevereiro/18/CARTILHA-Equidade-10x15cm.pdf >. Acesso em: 06 nov. 2016, p. 17.

56 "Trata-se de um desejo de viver e ser aceito enquanto pessoa do sexo oposto. Este desejo se acompanha em geral de um sentimento de mal estar ou de inadaptação por referência a seu próprio sexo anatômico e do desejo de submeter-se a uma intervenção cirúrgica ou a um tratamento hormonal a fim de tornar seu corpo tão conforme quanto possível ao sexo desejado". Cf. USP. Centro Brasileiro de Classificação de Doenças. Classificação Estatística Internacional de Doenças e Problemas Relacionados à Saúde - CID-10. Disponível

em: < http://www.datasus.gov.br/cid10/V2008/cid10.htm> Acesso em: 06 nov. 2016.

57 “CONSIDERANDO ser o paciente transexual portador de desvio psicológico permanente de identidade sexual, com rejeição do fenótipo e tendência à automutilação e/ou autoextermínio". Cf. CONSELHO FERAL DE MEDICINA. Resolução $n^{\circ} 1.955$ de maio de 2010. Dispõe sobre a cirurgia de transgenitalismo e revoga a Resolução CFM no 1.652/02. Diário Oficial da União. Brasília, 3 set. 2010, Seção I. p. 109110.

${ }^{58}$ LEAL, Jeferson. O corpo é meu! A vida é minha! A construção corporal de mulheres transexuais. 2016. $72 \mathrm{f}$. TCC (Graduação) - Curso de Serviço Social, Universidade Federal de Santa Catarina, Florianópolis, 2016, p. 11.

${ }^{59}$ BRASIL. Ministério da Saúde. Cuidar bem da saúde de cada um. Faz bem para todos, Faz bem para o Brasil. Brasília, DF, 2016. Disponível em: <http://portalsaude.saude.gov.br/images/pdf/2016/fevereiro/18/CARTILHA-Equidade-10x15cm.pdf>, p. 20-21.
} 
2.803/2013: a Atenção Básica que atende a população continuamente e é a porta de entrada prioritária das pessoas na rede de serviços do programa; e a Atenção Especializada, que por sua vez também se divide, primeiro na Modalidade Ambulatorial, responsável pelo acompanhamento clínico, o acompanhamento hormonal e, se necessário, o acompanhamento pré e pós-operatório. E a Modalidade Hospitalar, responsável pelas cirurgias cobertas pelo Processo e pelo acompanhamento pré e pós-operatório.

Como se verifica, o Processo Transexualizador do SUS proporciona às travestis e às transexuais algumas das modificações que desejam e acham importantes para a construção de sua imagem e identidade de gênero.

Contudo, ainda o faz por um viés patológico e preconceituoso, além de ser burocrático e demorado e contar com poucas unidades pelo Brasil, contraria os princípios constitucionais da dignidade da pessoa humana, da igualdade e do atendimento integral e universal do SUS, pois atende um número pequeno de travestis e pessoas trans.

\section{CONCLUSÕES}

Não obstante às inúmeras conquistas alcançadas nas últimas décadas pela comunidade LGBT, o Brasil ainda deve percorrer um longo caminho para que direitos básicos comuns a todas as pessoas sejam efetivados, como o acesso a saúde pública pelas travestis e mulheres trans, cujos corpos demandam uma atenção diferenciada.

Apesar da sexualidade ser um direito da personalidade, atrelado a dignidade da pessoa humana, a liberdade e a autodeterminação individual, a heteronormatividade imposta pela sociedade faz com que muitas pessoas da comunidade LGBT tentem adequar seus corpos ao binarismo, como por exemplo, as travestis e os transexuais. Não reconhecendo seu gênero como aquele que lhe foi imposto por seu sexo biológico ao nascer, elas precisam alterar sua imagem externa para que esta seja adequada ao seu real gênero, para isto se submetem a métodos e procedimentos clandestinos de modelagem, como a automedicação hormonal e a inoculação de silicone industrial líquido.

Esta prática clandestina é realizada pelas "bombadeiras", que realizam os procedimentos sem o preparo profissional adequado, sem condições mínimas de higiene, esterilidade e de produtos próprios. Exercem ilegalmente a medicina plástica estética, em que a sociedade faz "vista grossa" ao cometimento deste crime, de maneira que as "bombadeiras" somente são levadas a responder por seus ilícitos quando, por um erro, matam suas clientes.

Estas pessoas aceitam e assumem os riscos do uso prolongado e excessivo dos hormônios femininos e da inserção em seu organismo de silicone líquido, em nome de seus objetivos, ou seja, de um corpo feminino e dentro do padrão "mulherão" do Brasil.

Diante disto, não há dúvidas que a heteronormatividade associada à sociedade do espetáculo impõe padrão altíssimo de beleza, que jamais será alcançado, mas que será perseguido a qualquer preço por todas as pessoas, independentemente de seu sexo, gênero ou orientação sexual.

Infelizmente, o Brasil tem a maioria de suas políticas públicas de saúde voltadas para os heterossexuais. Para a comunidade LGBT existem apenas alguns programas de controle ao DTS e da AIDS, e na última década alguns mais específicos, mas insuficientes quanto ao número de serviços e ao número de atendimentos.

Para as travestis e mulheres trans se destaca o Processo Transexualizador do SUS, todavia é conduzido sob a orientação patologizada da travestilidade e da transexualidade, não buscando a promoção da saúde dessas pessoas, mas que tenta tratar uma doença (que não existe de fato).

Ademais, trata-se de um programa demorado e burocrático, que atende a um número 
ínfimo de indivíduos, o que ajuda a aumentar a discriminações em relação aos transgêneros não procura dessas pessoas pelos serviços clandestinos proporciona um acesso digno a saúde pública, das "bombadeiras" e optarem pela automedicação tampouco apresenta políticas públicas eficazes com hormônios.

para àqueles, fazendo com que recorram as

Por fim, a heteronormatividade imposta pela técnicas clandestinas de modificação corporal sociedade além de gerar preconceitos e realizada pelas bombadeiras.

\section{REFERÊNCIAS}

BENTO, Berenice. A reinvenção do corpo: sexualidade e gênero na experiência transexual. Rio de Janeiro: Garamond, 2006.

BRASIL é recordista mundial com 1,5 milhão de cirurgias plásticas ao ano (Profissão Repórter). Direção de Caco Barcellos. [S. 1.]: Globo Produções, 2015. Color.

BRASIL. Constituição (1988). Planalto. Brasília, DF. Disponível em: <http://www.planalto.gov.br/ccivil_03/constituicao/constituicaocompilado.htm>. Acesso em: 04 nov. 2016.

. Lei no 2.848, de 07 de dezembro de 1940. Código Penal. Planalto. Brasília, DF, 31 dez. 1940. Disponível em: <http://www.planalto.gov.br/ccivil_03/decreto-lei/Del2848compilado.htm>. Acesso em: 06 nov. 2016.

. Lei $\mathrm{n}^{\circ} 8080$, de 19 de setembro de 1990. Dispõe sobre as condições para a promoção, proteção e recuperação da saúde, a organização e o funcionamento dos serviços correspondentes e dá outras providências. Planalto. Disponível em: <http://www.planalto.gov.br/ccivil_03/leis/L8080.htm>. Acesso em: 05 mai. 2017.

Ministério da Saúde. Portaria $n^{\circ}$ 2.803, de 19 de novembro de 2013. Redefine e amplia o Processo Transexualizador no Sistema Único de Saúde (SUS). Brasília, DF: DOU, 21 nov. 2015. v. 226, Seção 1, p. 25.

Ministério da Saúde. Portaria $n^{o} 2.836$, de 01 de dezembro de 2011. Institui, no âmbito do Sistema Único de Saúde (SUS), a Política Nacional de Saúde Integral de Lésbicas, Gays, Bissexuais, Travestis e Transexuais (Política Nacional de Saúde Integral LGBT).

. Ministério da Saúde. Cuidar bem da saúde de cada um. Faz bem para todos, Faz bem para o Brasil. Brasília, DF, 2016. Disponível em: <http://portalsaude.saude.gov.br/images/pdf/2016/fevereiro/18/CARTILHA-Equidade10x15cm.pdf>. Acesso em: 06 nov. 2016.

Disponível Ministério da Saúde. Travesti e Resteito - Cartilha "Ser Travesti”. Brasília, DF, 2016. <http://www.aids.gov.br/sites/default/files/anexos_campanhas/2010/42751/cartilha.pdf>. Acesso em: 06 nov. 2016. 
. Ministério da Saúde. Conselho Nacional de Combate à Discriminação. Brasil Sem Homofobia: Programa de combate à violência e à discriminação contra GLTB e promoção da cidadania homossexual. Brasília: Ministério da Saúde, 2004.

BUTLER, Judith P. Problemas de gênero: feminismo e a subversão da identidade. 5. ed. Rio de Janeiro: Civilização Brasileira, 2013.

CARDIN, Valéria Silva Galdino; BENVENTUO, Fernanda Moreira. Do reconhecimento dos direitos dos transexuais como um dos direitos da personalidade. Revista Jurídica Cesumar do Mestrado, Maringá, v. 13, n. 1, p.113-130, jun. 2013.

COLAS, André. Silicones: Preparation, Properties and Performance. Disponível em: <https://www.dowcorning.co.kr/ko_KR/content/publishedlit/01-3077.pdf>. Acesso em: 05 nov. 2016.

CONSELHO FERAL DE MEDICINA. Resolução $n^{\circ} 1.955$ de maio de 2010. Dispõe sobre a cirurgia de transgenitalismo e revoga a Resolução CFM no 1.652/02. Diário Oficial da União. Brasília, 3 set. 2010, Seção I. p. 109-110.

DAVI, Edmar Henrique Dairell. Belíssima: um estudo merleau-pontyano da corporalidade travesti. 2013. 184 f. Tese (Doutorado) - Curso de Psicologia, Universidade de São Paulo, Ribeirão Preto, 2013.

DIAS, Maria Berenice. Liberdade sexual $e$ direitos humanos. Disponível em: <http://www.ibdfam.org.br/_img/congressos/anais/192.pdf>. Acesso em: 05 nov. 2016.

DORNELAS, Marilho Tadeu et al. Siliconomas. Rev. Bras. Cir. Plást., São Paulo, v. 26, n. 01, p.1621, jan/mar. 2011. Disponível em: <http://www.scielo.br/scielo.php?script=sci_arttext\&pid=S198351752011000100005>. Acesso em: 03 nov. 2016.

FOUCAULT, Michel. História da sexualidade I: a vontade de saber. 13. ed. Rio de Janeiro: Graal, 1999.

FREIRE FILHO, João. A sociedade do espetáculo revisitada. Revista Famecos, Porto Alegre, v. 10, n. 22, p. 33-46, dez. 2003. Disponível em: <http://revistaseletronicas.pucrs.br/ojs/index.php/revistafamecos/article/view/3230/2494>. Acesso em: 06 nov. 2016.

LEAL, Jeferson. $O$ corpo é meu! A vida é minha! A cotia-nstrução corporal de mulheres transexuais. 2016. 72 f. TCC (Graduação) - Curso de Serviço Social, Universidade Federal de Santa Catarina, Florianópolis, 2016.

LOPES, Teresa Ancona. O dano estético: responsabilidade civil. 3. ed. São Paulo: Revista dos Tribunais, 2004.

MELLO, Daniel Francisco et al. Complicações locais após a injeção de silicone líquido industrial: série de casos. Rev. Col. Bras. Cir, Rio de Janeiro, v. 40, n. 1, p.37-43, fev. 2013. Disponível em: <http://www.scielo.br/pdf/rcbc/v40n1/07.pdf>. Acesso em: 05 nov. 2016.

MOTT, Luiz. Antropologia, teoria da sexualidade e direitos humanos dos homossexuais. Bagoasestudos gays: gênero e sexualidades, Natal, v. 1, n. 1, p.1-15, jan. 2007. Disponível em: <https://periodicos.ufrn.br/bagoas/article/view/2252/1685>. Acesso em: 04 nov. 2016. 
NOGUEIRA, Francisco Jander de Sousa; LEÓN, Adriano Gomes de. "Trabalhadas no feminino": um estudo sobre corpo, desejo e prostituição travesti em Fortaleza-CE. Revista Latinoamericana de Estudios Sobre Cuerpos, Emociones y Sociedad, Córdoba, v. 4, n. 8, p.55-67,abr/ jul. 2012.

PAIVA, André Luiz dos Santos; FÉLIX-SILVA, Antônio Vladimir. Produção Protética dos Corpos: Experiências TRANS e Políticas de Saúde. Ártemis, João Pessoa, v. 18, n. 1, p.251-263, 31 dez. 2014. Revista Artemis. Disponível em: <http://periodicos.ufpb.br/index.php/artemis/article/view/22550/12513>. Acesso em: 03 nov. 2016.

PELÚCIO, Larissa. "Toda quebrada na plástica”: Corporalidade e construção de gênero entre travestis paulistas. Campos, Curitiba, v. 6, n. 1-2, p.97-112, 31 dez. 2005. Universidade Federal do Parana. Disponível em: <http://revistas.ufpr.br/campos/article/view/4509/3527>. Acesso em: 25 out. 2016.

PERILO, Marcelo et al. Entre a AIDS e a integralidade: travestis, transexuais, bissexuais, lésbicas e gays nas políticas públicas de saúde no Brasil. In: BORGES, Lenise Santana (Coord.). Políticas públicas para população LGBT no Brasil: um mapeamento crítico preliminar. Goiânia: UFG, 2009. Cap. 6. 6 p. 213-256. <https://www.sertao.ufg.br/up/16/o/politicaslgbt_saúde.pdf?1345091830>. Acesso em: 28 nov. 2016.

ROCHA, Francielle Lopes; CARDIN, Valéria Silva Galdino. Do discurso do ódio contra as minorias sexuais como um instrumento de exclusão social. In: SIQUEIRA, Dirceu Pereira; AMARAL, Sérgio Tibiriçá (Org.). Democracia, Liberdade e Justiça Social: Fundamentos para uma teoria jurídica do reconhecimento. Birigui: Boreal, 2015. Cap. X. p. 181-200.

SANTOS, Anne Rafaele Telmira. A experiência da hormonioterapia das transexuais em Maceió/AL. Latitude, Maceió, v. 7, n. 1, p.129-147, jun. 2013. Disponível em: <http://www.seer.ufal.br/index.php/latitude/article/view/1068>. Acesso em: 05 maio 2017.

SILVA JUNIOR, Jonas Alves da. Uma explosão de cores: sexo, sexualidade, gênero e diversidade. In: VIEIRA, Tereza Rodrigues (Org.). Minorias Sexuais: Direitos e Preconceitos. Brasília: Editora Consulex, 2012. Cap. 1.p. 11-27.

SILVA, Ilza Andrade Campos; OLIVEIRA, José Sebastião de. Direito à imagem e liberdade de expressão à luz dos direitos da personalidade. Revista Jurídica Cesumar: Mestrado, Maringá, v. 6, n. 1, p. 395-420, jan/jun. $2006 . \quad$ Disponível em: <http://periodicos.unicesumar.edu.br/index.php/revjuridica/article/view/319/178>. Acesso em: 04 nov. 2016.

SOANES, Catherine; STEVENSON, Angus (Ed.). Oxford Dictionary of English. 2. ed. Oxford: Oxford University Press, 2005. E-book.

USP. Centro Brasileiro de Classificação de Doenças. Classificação Estatística Internacional de Doenças e Problemas Relacionados à Saúde - CID-10. Disponível em: < http://www.datasus.gov.br/cid10/V2008/cid10.htm> Acesso em: 06 nov. 2016.

VIEIRA, Tereza Rodrigues. Nome e sexo: mudanças no registro civil. 2. ed. São Paulo: Atlas, 2012. 
Recebido em: 27/09/2017 Aceito em: 10/12/2017 
